\section{Characteristics of Human Natal Stem Cells Cultured in Allogeneic Medium}

\author{
Jakub Suchánek ${ }^{1}$, Klara Zoe Browne ${ }^{2}$, Sherine Adel Nasry³, Tereza Suchánková
} Kleplová', Nela Pilbauerová1, Jan Schmidt ${ }^{1}$, Tomáš Soukup ${ }^{2}$

\author{
'Department of Dentistry, Charles \\ University, Faculty of Medicine in \\ Hradec Králové and University Hospital \\ Hradec Králové, Czech Republic \\ ${ }^{2}$ Department of Histology and \\ Embryology, Charles University, \\ Faculty of Medicine in Hradec \\ Králové, Czech Republic \\ ${ }^{3}$ Surgery and Oral Medicine \\ department, Oral and Dental \\ Research Division, National \\ Research Centre, Cairo, Egypt \\ Correspondence: Sherine Adel \\ Nasry, Oral and Dental Research \\ Division, National Research Centre, \\ 3 El Buhouth Str, Dokki, 12622. \\ Tel.: +2 01223134144. e-mail:
} ghattassherine@gmail.com
Recently, human natal dental pulp stem cells (hNDP-SCs) have been characterized in vitro and it has been shown that they satisfy criteria defining human mesenchymal stromal results were reached in the presence of xenogeneic expansion medium, which has the potential to alter the cells' functional capacity. To determine the validity of the previously reported hNDP-SCs characteristics for human cell therapy, we have cultured hNDP-SCs in allogeneic expansion medium. Two hNDP-SC lineages were isolated from vital natal teeth, donated by a healthy newborn female and cultured in 2\% platelet rich plasma (PRP). Analysis of the phenotypic expressions, proliferation rates, viability, telomerase length and in vitro adipogenic, osteogenic and chondrogenic differentiation potentials of two hNDP-SCs lineages (Zn001 and Zn002) were performed. Both lineages displayed similar morphology, proliferation rates, adipogenic, chondrogenic and osteogenic differentiation potential. Telomere shortening by $41.0 \%$ and $13.49 \%$ occurred from 3rd till 14 th passage for lineages Zn001 and Zn002 respectively. Viability of both lineages was higher than $90 \%$. Flow cytometry demonstrated that both lineages were positive to the majority of tested markers, including markers, which were negatively, expressed when hNDP-SCs were cultured previously in xenogeneic medium. Using immune-cytochemistry the cells were shown to express beta III-tubulin, nestin, neurofilaments and Nanog. PRP used as allogeneic medium is suitable for cultivation of hNDP-SCs.
Key Words: natal, dental pulp, platelet-rich plasma, allogeneic, stem cell

\section{Introduction}

Therapeutically potent populations of human dental pulp mesenchymal stromal cells (DP-MSC) can be isolated from young pulp tissues of teeth of both normal dentitions i.e. primary and secondary dentition, as well as from pulp tissues of supernumerary teeth of dentitia praecox. While these populations do share some basic characteristics, they express heterogeneity in proliferative and regenerative capacities, which is related to their contrasting agedependent telomere lengths and CD271 expression (1).

Hierarchically the youngest population of DP-MSC is enclosed in natal teeth and neonatal teeth. The natal teeth erupt into oral cavity at birth, while the neonatal teeth erupt within the first 30 days after birth (2). These are either supernumerary predeciduous teeth $(<10 \%)$ or prematurely erupted deciduous series of teeth (>90\%) (3), which tend to appear in place of lower primary central incisors (85\%). Overall, this is a low-incidence phenomenon at 1:3000 of births, where the vast majority of these teeth are indicated for extraction, because of the potential risk to the infant and mother (4). Human natal dental pulp stem cells (hNDP-SCs) have been recently isolated, cultured (in MEM medium containing 15\% fetal bovine serum) and characterized by Karaöz et al. (5) and Akpinar et al. (6), who both described the hNDP-SCs as metabolically active stem cell-like population, which expresses MSCs and embryonic stem cell markers but do not exhibit expression of hematopoietic markers.

The hNDP-SCs were reported to have shown aptitude for trilineage differentiation; and in comparison to SHED (stem cells from human exfoliated deciduous teeth) and DPSC (dental pulp stem cells) their proliferation activity was higher and their telomerase activity was greater (6). To yield qualitative data about population of any DP-MSC ex vivo, it first has to be expanded, as its volume at isolation is insufficient. For the research existing data to further present a credible advice to human cell therapy, as per the U.S. current good manufacturing practice (cGMP) guidelines and the EU Tissues and Cells Directive (2004/23/EC), the original cell population is to be expanded and further cultured under such conditions. This minimises the risks of lot-to-lot variability, contamination and immunization due to viral infection or internalized xenogeneic proteins, as stated $(7,8)$. To ensure these conditions are met researchers must implement multiple measures, such as verification of reagent quality and purity of the entering biological material, as well as validity of the research protocol itself.

According to a previous study, the hNDP-SCs characterization is to be considered indicative only and unsatisfactory to draw implications for human cell therapy, due to the critical research protocol shortcoming in the adoption of xenogeneic serum (5). 
Meanwhile, there are two remaining expansion and cultivation media options for research aimed at human cell therapy. These are the chemically defined serum-free media and the allogeneic serum-containing media; here the allogeneic serum is derived from various sources e.g. human umbilical cord blood, human blood, human plasma and platelet lysate (9). Even though the chemically defined serum-free medium would be ideal for exploratory research such is the characterization of new cell line, ensuring its reproducibility and excluding further uncontrollable variables, such product is nevertheless not yet developed to effectively address the needs of the DP-MSCs in vitro (10). As far as allogeneic-sera are concerned, it was proven that human platelet-rich plasma (PRP) performed superior to FCS and therefore can be used as its adequate replacement (11).

The aim of this study was to characterize the hNDPSCs' phenotypic expression, proliferation rate, telomerase activity and in vitro adipogenic, osteogenic and chondrogenic differentiation potential; when cultured in xenogeneic free medium.

\section{Material and Methods}

\section{Isolation and Amplification of hNDP-SCs}

Two hNDP-SCs lineages were isolated from natal teeth donated by healthy newborn female. The natal pulp tissue was treated according to allogeneic human dental pulp derived MSCs amplification and differentiation protocols described previously (12). Briefly, isolated cells were seeded onto culture flasks containing xenogeneicfree cultivation media composed of $\alpha$-MEM (Invitrogen, Waltham, MA, USA), $10 \mathrm{ng} / \mathrm{ml}$ EGF, $10 \mathrm{ng} / \mathrm{ml}$ PDGF (both PeproTech, UK), $0.1 \mathrm{mg} / \mathrm{ml}$ L-ascorbic acid (SigmaAldrich, MO), 2\% glutamine (Invitrogen, USA), 0.6\% penicillin/streptomycin (Invitrogen), 0.5\% gentamycin (Invitrogen), 8\% dexamethasone (Sigma-Aldrich, St. Louis, MO, USA), and supplemented with insulin-transferrinsodium-selenite supplement (ITS) (Sigma-Aldrich) at a concentration of $10 \mu \mathrm{L} / \mathrm{mL}$ and 2\% PRP (Transfusion department, University hospital Hradec Králové, Czech Republic). To decrease sampling bias the PRP used was pooled from five different donors. Consecutively, the pellets were incubated at $37{ }^{\circ} \mathrm{C}$, in a humidified atmosphere containing $5 \% \mathrm{CO}_{2}$. The cells, which adhered to the flask, were isolated as a population of stem cells and seeded onto new culture flasks, labeled passage 1 , passage 2 onward, cells were seeded in density of 5000 cells $/ \mathrm{cm}^{2}$ and harvested after reaching $70 \%$ confluence. Growth medium was replaced every 3-4 days.

\section{Cell Proliferation and Viability}

To test hNDP-SCs self-renewal ability, we have cultivated them beyond the Hayflick's limit (50 CPD cumulative population doublings) (13). The lineages' proliferation activity was measured every passage on Z2 counter and their viability was measured on cell samples obtained from $3^{\text {rd }}$ and $11^{\text {th }}$ passage using Vi-Cell Analyser (both Beckman Coulter, Brea, CA, USA).

\section{Phenotypic Identification}

To identify phenotypic characteristics of hNDP-SCs amplified in xenogeneic-free medium in-vitro; both undifferentiated lineages were subjected to flow cytometry analysis. Cells from passage five were harvested, suspended in culture medium and stained with immunofluorescent primary antibodies: anti-CD10 (eBiosciences, Clone:CBCALLA), anti-CD13 (eBiosciences, Clone:WM-15), antiCD29 (BD Biosciences Pharmingen, Clone:TS2/16), anti-CD34 (Beckman Coulter, Clone:581), anti-CD44 (BioLegend, Clone:IM7), anti-CD45 (eBiosciences, Clone:HI30), anti-CD71 (BioLegend, Clone:MEM-75), anti-CD73 (BD Biosciences Pharmingen, Clone:AD2), anti-CD90 (Beckman Coulter, Clone:F15-42-1-5), anti-CD105 (BioLegend, Clone:MEM-226), anti-CD146 (Beckman Coulter, Clone:TEA1/34), anti-CD166 (Beckman Coulter, Clone:3A6), anti-CD184-CXCR4 (Caltag, Clone:12G5), anti-CD222 (eBiosciences, Clone:MEM-238), anti-CD271 (BioLegend, Clone:ME20.4), anti-INF beta (INFsource, Clone:MMHB-3), anti-0CT3/4 (eBiosciences, Clone:EM92) and anti-HLA I (Caltag, Clone:Tül49) using Cell Lab Quanta analyser (Beckman Coulter). Percentage of positive cells was determined as the percentage of cells with higher fluorescence intensity than $99.5 \%$ isotype immunoglobulin control.

\section{Immunostaining}

To identify specific biomolecule targets within hNDPSCs we have performed immunofluorescence staining. The cells from passage seven were detached from cultivation dish and fixed in 10\% neutral buffered formalin solution for five days. Subsequently, the pellets were submerged in PBS with 5\% blocking serum (Sigma, from the same species as primary antibody) for $30 \mathrm{~min}$, to prevent false positive results. The samples were then incubated with primary antibodies for $90 \mathrm{~min}$. The studied antigens and the corresponding primary antibodies used were: beta3-tubulin (TU-20, 1:50, Exbio), nestin (10C2, 1:200, Chemicon, USA), neurofilaments (DA2, FNPT, prediluted, Zymed), SOX2 (rabbit polyclonal, 1:100, Chemicon), and Nanog (rabbit polyclonal, 1:200, Abcam). After PBS washes, pellets were incubated with appropriate secondary antibodies conjugated with fluorochromes for $30 \mathrm{~min}$, to visualize the antigen-binding sites. The cell nuclei were visualized using DAPI (Sigma-Aldrich). 


\section{Measurement of Telomere Length}

Telomere length was measured using qPCR according to previously described protocol (14). Genomic DNA was extracted from hNDP-SCs obtained from 3rd and 14th passage using DNeasy Tissue Kit (Oiagen, Germany). T/S ratio (telomere repeat copy number/single-gene copy number) was determined as: $\mathrm{T} / \mathrm{S}=2-\Delta \mathrm{Ct}$ (where $\Delta \mathrm{Ct}=$ Cttelomere - Ctsingle-copy gene). 36B4 was used as the single copy gene. Telomere qPCR were done using 200 nM telomere forward primer (CGG-TT-GT-TGG-GTTGG-GT-TGG-GT-TGG-GT-TGG-GT), $200 \mathrm{nM}$ telomere reverse primer (GGC-TTG-CCT-TAC-CCT-TAC-CCT-TACCCT-TAC-CCT-TAC-CCT) and for 36B4 gene qPCR the following primer-pairs were used: $36 \mathrm{~B} 4 \mathrm{u}, \mathrm{CAG}-\mathrm{CAA}-\mathrm{GTG}-$ GGA-AGG-TGT-AAT-CC; 36B4d, CCC-AT-CTA-TCA-TCAACG-GGT-ACA-A.

Relationship between the average telomere length and the selected parameters was determined by correlation analysis performed in GraphPad Prism 5.01 statistical software. Differences were considered statistically significant when $p<0.05$.

\section{In-Vitro Differentiation}

hNDP-SCs from 4th passage were seeded onto culture dish containing differentiation media. Differentiation media were changed every 3-4 days.

\section{Adipogenic Differentiation}

For adipogenic differentiation, the hNDP-SCs were incubated in adipogenic differentiation medium (Cyagen Biosciences, Santa Clara, CA, USA) for four weeks. For adipogenic differentiation the cells were fixed within the cultivation flask in 10\% neutral buffered formalin solution for 10 minutes and stained with $0.18 \%$ Oil Red 0 (Sigma-Aldrich,) to detect the presence of intracellular lipid droplets indicating adipogenic differentiation.

\section{Osteogenic Differentiation and Chondrogenic Differentiation}

The osteogenic differentiation media was composed of alpha-MEM, $0.5 \mathrm{mM}$ ascorbic acid, $10 \mathrm{mM}$ of $\beta$-glycerophosphate, $0.1 \mu \mathrm{M}$ of dexamethasone and $10 \%$ PRP. The chondrogenic differentiation was triggered using cultivation media minus PRP, which was substituted by 50 ng/mL TGF- $\beta 1$ (Stem Cell Technologies, Canada).

After four weeks differentiated cells were harvested using cell scraper and the resulting pellet was fixed in 10\% neutral buffered formalin solution for five days. Osteogenic differentiation was confirmed via Alizarin-red and von Kossa-staining, which visualises calcium deposits. The chondrogenic differentiation was confirmed via Alcian-blue staining which elucidate acid mucopolysaccharides.

\section{Results}

Cell Proliferation and Viability

In both lineages of hNDP-SCs first colonies of adherent cells appeared after the initial 11 days of cultivation (Fig. 1A). The surface morphology of not fully confluent hNDP-SCs was round with elongated processes which were reaching the surrounding cells (Fig 1B). When fully confluent the cells showed standard dental related stem cells morphology, they had spindle shaped surface morphology with elongated processes (Fig. 1C, D).

Average population doublings (APDs) per passage by lineage was: Zn001 $4.21 \pm 2.80$ \& Zn002 $4.15 \pm 3.22$ (Fig. 2A). hNDP-SCs were successfully expanded over 50 cumulative population doublings (CPDs), reaching Hayflick's limit, within the first 15 passages (Zn001 58.92 CPDs; Zn002 58.16 CPDs) (Fig. 2 B).

Average doubling time per passage (ADT) by lineage was: Zn001 $38.87 \pm 15.38$ \& Zn002 $44.64 \pm 23.82$ h (Fig. 2C).

During long term cultivation both lineages showed high and stable proliferation rate between passages 1-7, while the PD from passage 8-onwards kept on gradually decreasing (Zn001: passage 1-7: $5.24 \pm 0.61$ APDs; 26.80 \pm 5.47 ADT; reached 39.78 CPDs; passage 8-14: $3.16 \pm$ 0.36 APDs; $49.2 \pm 10.06$ ADT; reached 19.13 CPDs. Zn002: passage 1-7: $5.31 \pm 0.60$ APDs; $28.87 \pm 8.89$ ADT; reached 40.86 CPDs; passage 8-14: $3.02 \pm 0.86$ APD; $58.59 \pm 18.84$ ADT; reached 17.31 CPDs (Fig. 2 D-F).

Viability was measured twice, at passage 3 and 11, and in all samples was higher than 90\% (Zn001 97.2/ 92.0\% and Zn002 93.4/ 91.8\%).

\section{Phenotypical Analysis}

Flow cytometry showed that our lineages of hNDPSCs were highly positive ( $>95 \%)$ to the majority of tested markers,

Using immunocytochemistry we have proven that undifferentiated hNDP-SCs are betalll-tubulin (Fig. 3C), nestin (Fig. 3 D), neurofilaments (Fig. 3 E), SOX 2 (Fig. 3F) and Nanog (Fig. 3 G) - positive cells.

\section{Telomere Length}

For lineage Zn001 in $3^{\text {rd }}$ passage (22.35 PD) the $\mathrm{T} / \mathrm{S}$ was 2.69 and in $14^{\text {th }}$ passage (58.92 PD) $\mathrm{T} / \mathrm{S}$ was 1.58 . This represents telomere shortening by $41.0 \%$ during 36.57 PD.

For lineage $\mathrm{Zn002}$ in $3^{\text {rd }}$ passage (23.86 PD) the T/S was 1.43 and in $14^{\text {th }}$ passage (56.51 PD) T/S was 1.58. This represents telomere shortening by $13.49 \%$ during $32.65 \mathrm{PD}$.

\section{In Vitro Differentiation}

Using standardized differentiation protocols and 

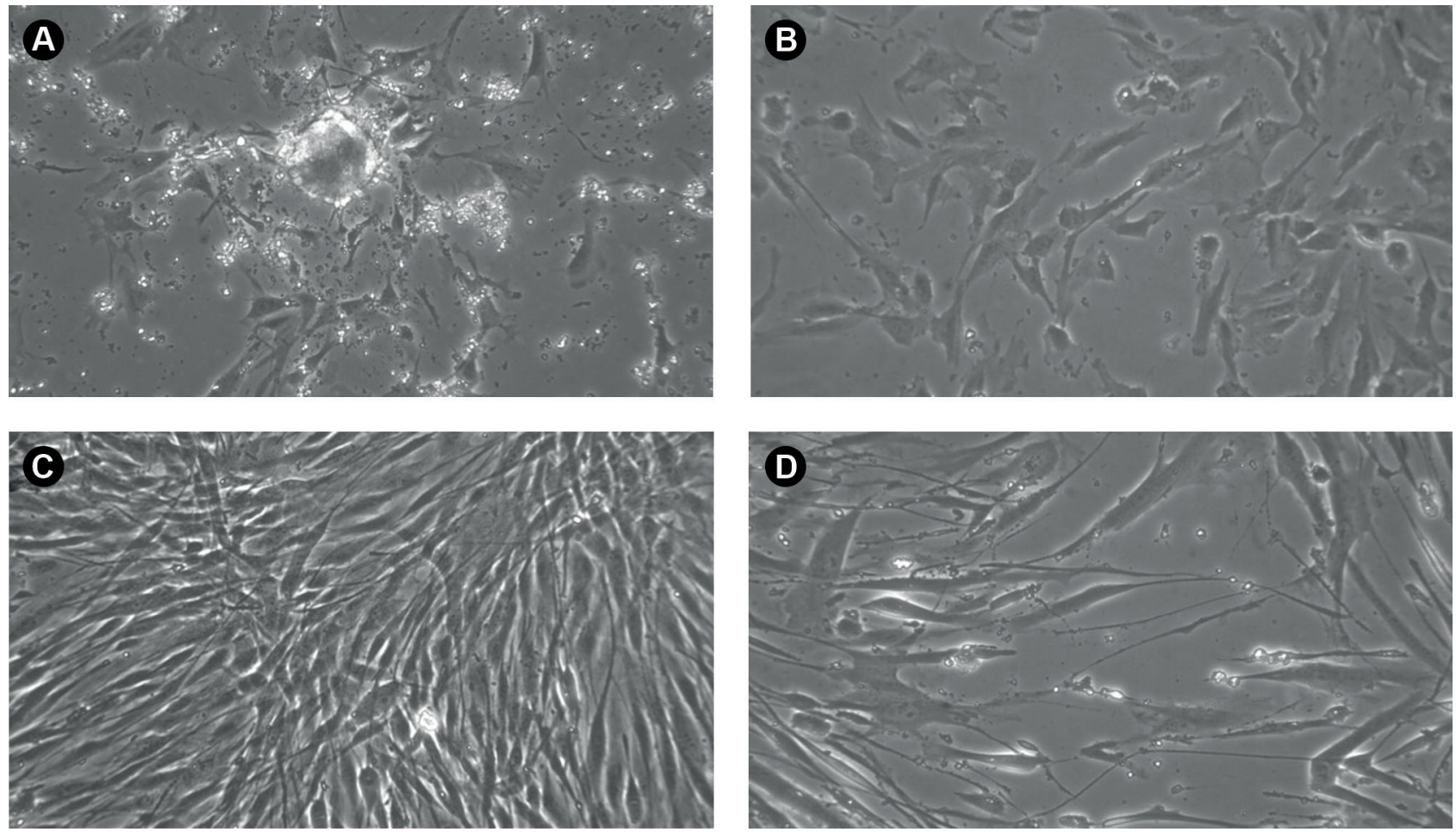

Figure 1. A: lineage Zn002 14 days after isolation: we can observe small colonies containing about 30 cells, B: lineage Zn002 in the second passage 2 days after seeding: cells adhered more to the surface of cultivation dish, became flattened and rounded; C: lineage Zn002 at 2 th passage 4 days after seeding: cells reached almost $100 \%$ confluence, maintaining the normal morphology of DPS, being spindle shaped with long processes, D: Zn001 at 14th

$\vec{\approx}$ passage 7 days after seeding: confluence reached was about $60 \%$, cells kept the spindle shape morphology. Phase contrast microscopy magnification 200 . i

\begin{tabular}{l|r|r}
$\mathbf{A}$ & \multicolumn{1}{|l|}{ Zn001 } & Zn002 \\
\hline CD10 & 99,83 & 99,81 \\
\hline CD13 & 99,80 & 99,97 \\
\hline CD29 & 99,76 & 99,98 \\
\hline CD34 & 87,44 & 82,53 \\
\hline CD44 & 99,72 & 99,98 \\
\hline CD45 & 95,54 & 96,49 \\
\hline CD71 & 97,00 & 97,31 \\
\hline CD73 & 99,72 & 99,95 \\
\hline CD90 & 99,87 & 99,99 \\
\hline CD105 & 99,95 & 99,98 \\
\hline CD146 & 99,87 & 99,94 \\
\hline CD166 & 99,96 & 99,98 \\
\hline CD222 & 99,44 & 99,46 \\
\hline CD271 & 96,51 & 95,80 \\
\hline OCT3/4 & 99,74 & 99,80 \\
\hline CXCR4 & 99,02 & 98,57 \\
\hline INF beta & 98,54 & 97,81 \\
\hline HLA DR & 99,32 & 99,43
\end{tabular}

B Phenotype identification
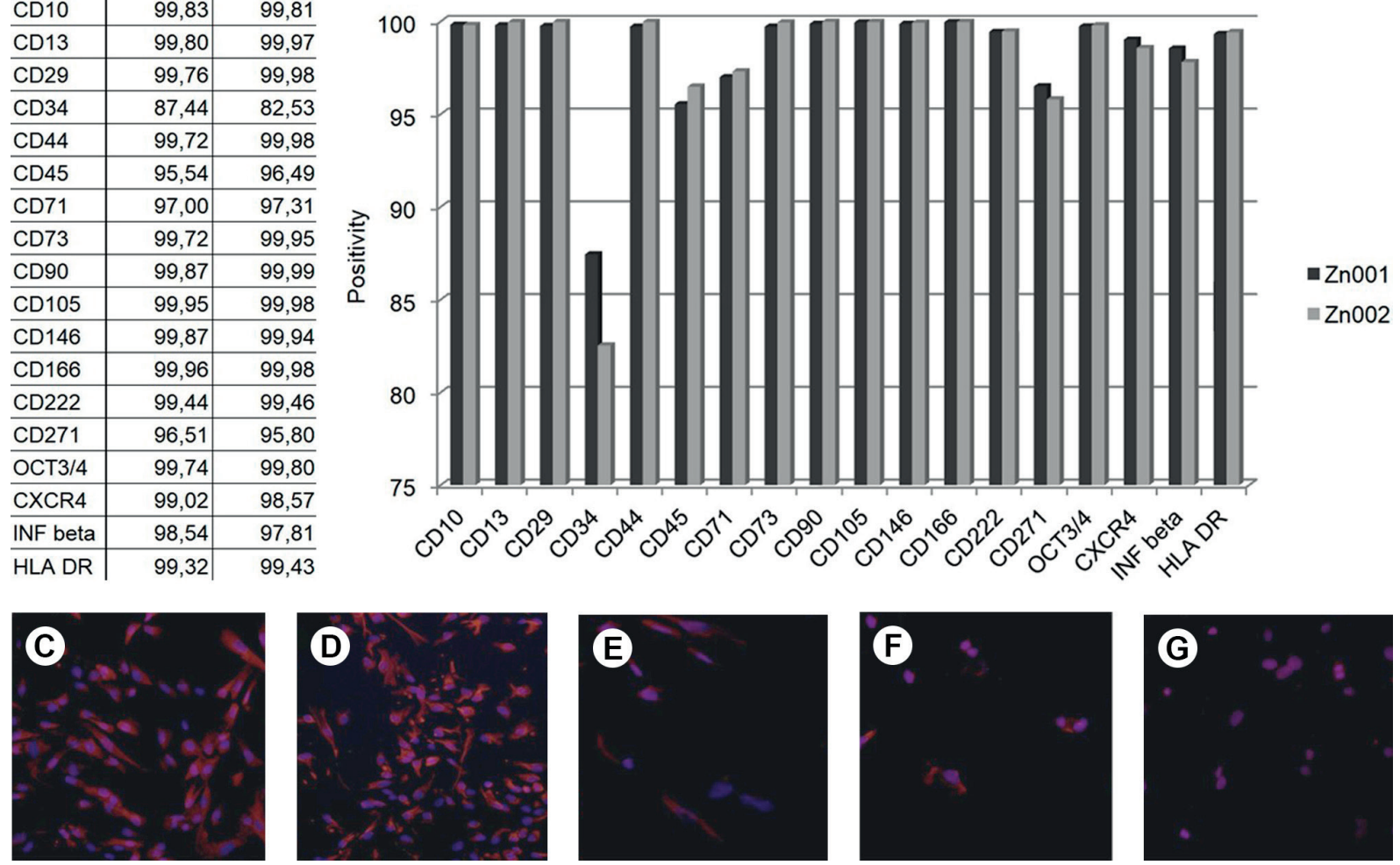

Figure 2. A: number of population doublings done during each passage, B: Cumulative number population doublings show linear growth during each passage, C: time in hours needed for doubling the population shows decreased proliferation rate after the 7th passage, D-F: comparison of hNDP-SCs' proliferative capacity in 1st- 7th passage and 8 th-14th passage 
histological staining we proved the ability of human natal tooth dental pulp stem cells to all three recommended mature cell types:

In vitro osteogenic differentiation - Using Von Kossa staining and Alizarin red staining we proved the presence of calcium deposits within the extracellular matrix comparing with the negative control (Fig. 4A-D)

In vitro chondrogenic differentiation - To visualise the
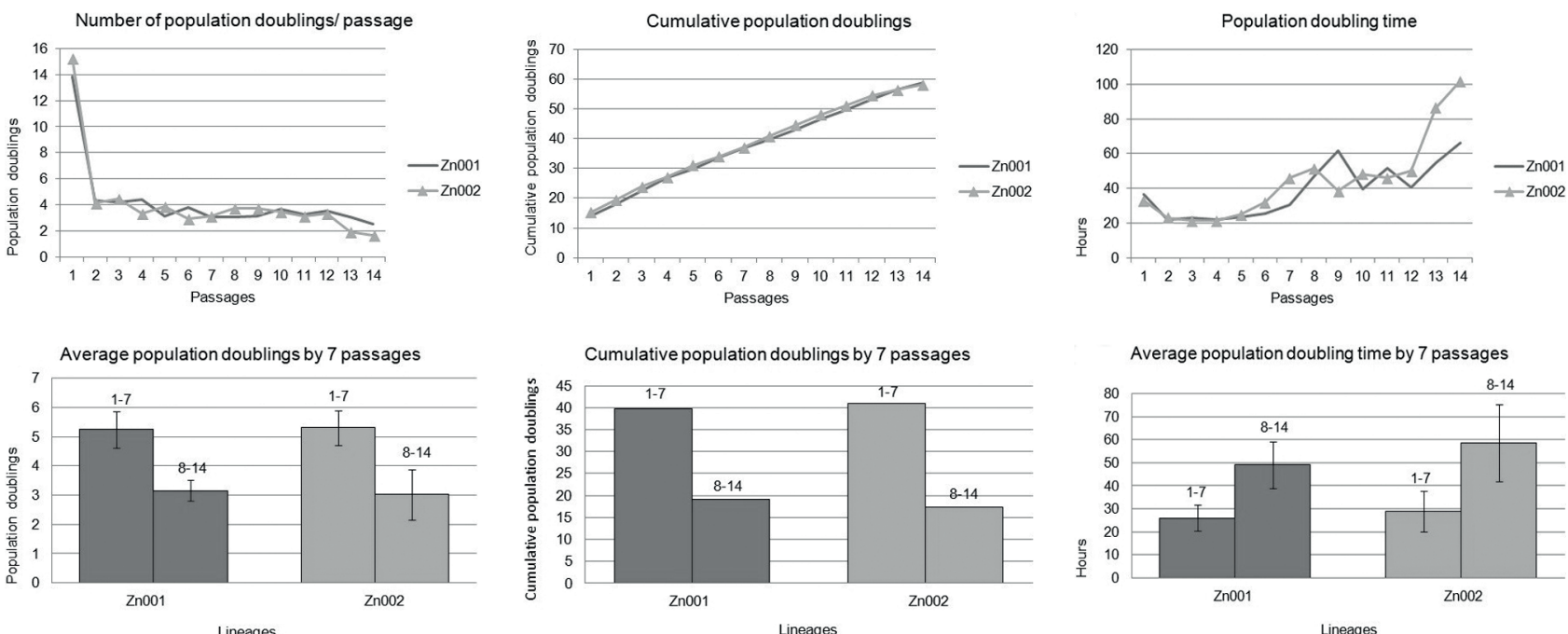

Figure 3. Flow cytometry and cell immunofluorescence of cultured hNDP-SCs: A-B: expression of cell surface markers of undifferentiated hNDPSCs. C: beta3-tubulin and D: nestin were detected within the cytoplasm of all cells, E: neurofilaments were localized surrounding the cell nuclei with fading out concentration towards the cell peripheral sites, F: Sox 2 was mostly detectable just in the area of cell nuclei with very low concentration in the surrounding cytoplasm and G: Nanog was localized just within the area closest to the nuclei and therefore most of it expression is covered by DAPI signal of nuclei. Samples were examined with BX51 microscope (Olympus) equipped with DP71 digital camera.
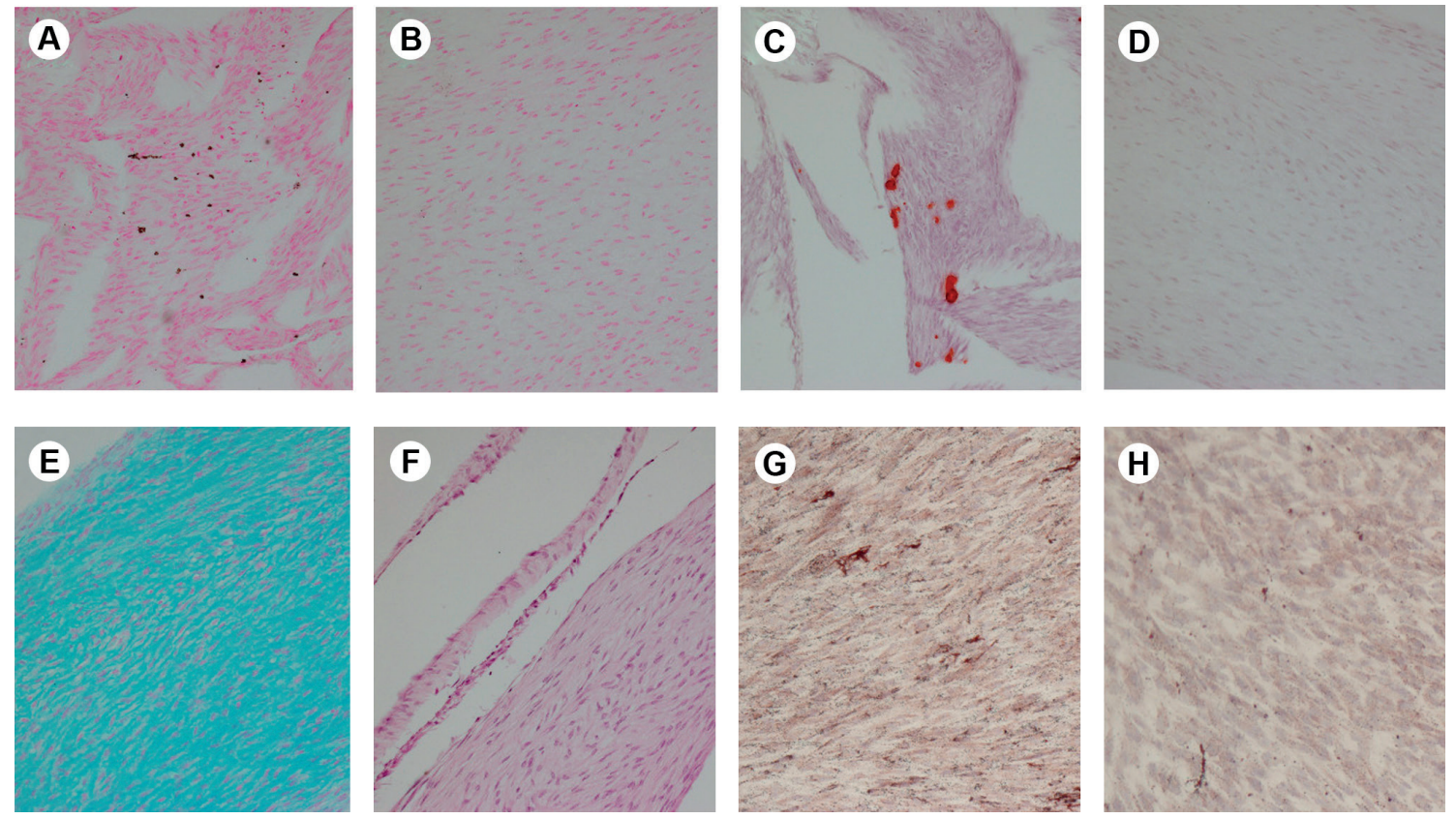

Figure 4. Histological slides comparing differentiated hNDP-SCs lineages to negative control: A: osteo-differentiated hNDP-SCs stained by Von Kossa technique - brown color visualized calcified extracellular particles, B: undifferentiated hNDP-SCs stained by Von Kossa technique, C: osteo-differentiated hNDP-SCs stained by Alizarin red technique - red color visualized calcified extracellular particles; D: nondifferentiated hNDP-SCs stained by Alizarin red technique; E: chondro-differentiated hNDP-SCs stained by Alcian blue - blue colour indicate the presence of acid mucopolysaccharides, purple color indicates the cell nuclei; F) undifferentiated hNDP-SCs stained by Alcian blue technique; G: adipo-differentiated hNDP-SCs stained using Oil red staining. Dark red color indicates the presence of lipid vacuoles within the cells; H: undifferentiated hNDP-SCs stained using Oil red staining. All slides were taken using 100x magnification microscope. 
presence of acid mucopolysaccharides, which represents typical cartilage extracellular matrix, the differentiated cells were stained by Alcian blue (Fig. 4 E, F).

In vitro adipogenic differentiation - The presence of lipid droplets within the cells, which is the typical mark for adipocytes, the differentiated cells were stained by Oil red staining technique (Fig. $3 \mathrm{G}, \mathrm{H}$ ).

\section{Discussion}

Although fruitful research on the use and characterization of MSCs have been documented using xenogeneic serum as culture medium, the serious medical problems that this serum can cause to human recipients has directed many researchers to the use of xenogeneic-free medium, such as chemically-defined serum-free medium and the allogeneic human serum-containing medium. PRP as allogeneic serum-containing medium has shown to be a suitable cultivation media for MSCs of dental sources (10).

In the present study we attempted to analyze the phenotypic expression, proliferation rate, telomere length and multilineage differentiation of hNDP-SCs cultured in xenogeneic-free medium in order to determine the validity of hNDP-SCs for human cell therapy.

The ability of self-renewal and multilineage differentiation potential of SCs are crucial in SC therapy. Results of this study demonstrated successful differentiation of hNDP-SCs to adipogenic, chondrogenic and osteogenic lineages, which is in line with previous research (6). In addition to those three lineages, hNDP$\mathrm{SC}$ s were also shown to express myogenic and neurogenic markers and possess the ability to differentiate into mature myoblasts and neuroglial cells, which denotes the diverse immunophenotypic characteristics of MSCs (5). A recent work demonstrated for the first time the ability of hNDP-SCs to also differentiate to insulin producing results confirming their diverse phenotypic quality (15).

Many scientific studies have shown a strong connection between short telomeres and cellular aging, as telomeres serve as a bioprotective mechanism of chromosome attrition at each cell division (16). The present study demonstrated a $41 \%$ decrease in telomere length in Zn001 lineage in comparison to a $13.49 \%$ decrease in Zn002 lineage from the $3^{\text {rd }}$ (Zn001 22.35/ Zn002 23.86 PD) till $14^{\text {th }}$ (Zn001 58.92/ Zn002 58.16 PD) passage. Our findings are in agreement with previous research that demonstrated MSCs, telomerase activity to be highest in early passages $(17,5)$. When comparing telomerase activity between hNDP-SCs and that of hBM-MSCs, it was observed that the telomerase activity was high in hNDP-SCs while no activity was detected in hBM-MSCs, suggesting that hBM-MSC should be using other mechanism for telomere maintenance (5).
Using PRP as allogeneic medium in this study, hNDP-SCs were successfully expanded over 50 cumulative population doublings and demonstrated high and stable proliferation rate. The higher proliferation rate of hNDP-SCs could be attributed to the embryonic nature of SCs obtained from natal teeth. When 15\% FBS as culture medium in previous work, hNDP-SCs demonstrated a marked capacity to proliferate, preserving their growth rate for more than 25 passages (5). In our study high and stable proliferative rate was observed from the 1st till the 7th passages in both cell lineages, but then the PD kept decreasing starting passage 8 . When considering results of previous research comparing the effect of different serum concentration on the proliferative capacities of SCs, DPSCs cultivated in media containing 10\% PRP proliferated faster than those cultivated in media containing 2\% PRP, 2\% FCS and $10 \%$ FCS (11). Other findings demonstrated that a culture medium containing 10\% PRP was able to boost the SHED proliferation capability more than $2 \%$ PRP culture medium, while 2\% FCS demonstrated better results than 10\% FCS containing medium, with regards to the SC proliferation capacity. The authors attributed these results to the toxicity of using the higher concentration of 10\% FCS when compared to $2 \%$, a finding which contradicts results of Karaöz et al. (5) and Suchanek et al. (10).

An interesting finding was the positivity (>95\%) of hNDP-SCs cultured in xenogeneic-free medium to the majority of tested markers, which is in contrast with previous results that have shown negative expression of these markers $(<2 \%)$ when hNDP-SCs were cultured under xenogeneic conditions $(5,6)$. The only marker showing lower positivity was CD34 (82-88\%).

The expression of embryonic stem cell markers including OCT4, Sox2, Nanog and Rex1 was shown to be higher than that of SHED and permanent teeth in previous studies. Determination of the transcript levels of embryonic SCs genes (Rex-1, Oct-4, Nanog) reflects the propensity for hNDP-SCs for pluripotency. Using immunocytochemistry we highlighted the positivity of hNDP-SCs for beta IIItubulin, nestin and neurofilaments, which is consistent with previous findings were neural progenitor markers were expressed by both hNDP-SCs and hBM-MSCs (human bone marrow mesenchymal stem cells), such uch as nestin and vimentin, as well as neuronal, markers as c-fos, $y$-enolase, beta III-tubulin and MAP2a,b. The expression of pluripotent markers and the higher proliferation rate of hNDP-SCs then SHED and DPSCs obtained from permanent teeth was said to reflect the immature embryonic characteristics of SC obtained from the pulp of natal teeth. Which is in agreement of the present findings $(5,6)$.

There have been controversial opinions regarding the expression of CD34 and CD45 in MSC. CD34 and CD45 have 
been related to hematopoietic cells and former researchers identified certain markers that were specific for MSCs as STRO-1, CD29, CD44 and CD13 while other markers as CD34, CD45, CD14 were considered hematopoietic cell markers and were not expressed by MSCs (18-21). It was shown that CD34 could be expressed by more MSC isolated from sources other than bone marrow, such as adipose tissue, as well as other non-hematopoietic cells (22-24). Low expression of CD34 was observed in SCs isolated from SHED (25) and SCs isolated from the pulp of permanent teeth were positive for expression of CD44 and CD90, CD73 and negative for expression of CD34 and CD45 (26). Studies have also demonstrated that CD34 in MSC are present shortly following tooth extraction but then their numbers decrease rapidly after a short time of being cultured $(27,28)$.

Our results indicate that hNDP-SCs expressed both MSCs markers, as well as hematopoietic cell markers as CD34 and CD45. Former research showed the expression of CD34 on embryonic stem cell derived MSC, suggesting it to be a marker of early human MSC (29), which could be the explanation for the expression of those markers in our study and points out the immature nature of natal cells in the present work. Another explanation for the expression of hematopoietic markers in our work might be the use of PRP as culture medium, as it was shown that the media used for cell culture could temper with the phenotypic characteristics of the cultured cells (10). This could be the reason behind the expression of other cell markers as CD13 and HLA-DR, which were not expressed when xenogeneic medium was used in SC culture in previous work $(5,6,30)$. Moreover in vitro characterization takes place primarily after several cell passaging following culture, and could not represent thein vivo or initially extracted cell phenotype.

Based on the results of the present study it may be concluded that PRP used as an allogenic medium is suitable for cultivation of hNDP-SCs.

\section{Resumo}

Recentemente, células-tronco da polpa dental humana (hNDP-SCs) foram caracterizadas in vitro e foi demonstrado que elas satisfazem critérios que definem células mesenquimais do estroma humana (MSCs), tal como proposto pela Sociedade Internacional para Terapia Celular. No entanto, esses resultados foram alcançados na presença de meio de expansão xenogênico, que tem o potencial de alterar a capacidade funcional das células. Para determinar a validade das características das hNDP-SCs anteriormente relatadas para a terapia celular humana, cultivamos hNDP-SCs em meio de expansão alogênico. Duas linhagens hNDP-SC foram isoladas de dentes natais vitais, doadas por uma recém-nascida saudável, e cultivadas em plasma rico em plaquetas a 2\% (PRP). Análises das expressões fenotípicas, taxas de proliferação, viabilidade, comprimento de telomerase e potenciais de diferenciação adipogênica, osteogênica e condrogênica in vitro das duas linhagens hNDP-SC (Zn001 e Zn002) foram realizadas. Ambas as linhagens apresentaram morfologia, taxas de proliferação, potencial de diferenciação adipogênico, condrogênico e osteogênico semelhantes. 0 encurtamento dos telômeros em $41,0 \%$ e
13,49\% ocorreu da 3a até a 14a passagem para as linhagens Zn001 e Zn002, respectivamente. A viabilidade de ambas as linhagens foi superior a $90 \%$. A citometria de fluxo demonstrou que ambas as linhagens foram positivas para a maioria dos marcadores testados, incluindo marcadores, que foram negativamente expressados quando hNDP-SCs foram previamente cultivadas em meio xenogênico. Usando análise imunocitoquimica, as células mostraram expressar a beta III-tubulina, nestina, neurofilamentos e Nanog. 0 PRP usado como meio alogênico mostrou-se adequado para o cultivo de hNDP-SCs.

\section{Acknowledgements}

The work was funded by Charles University, Faculty of Medicine, Hradec Králové, Czech Republic, project no. No. PROGRES 040/6 and PROGRES 040/13. All authors declare no conflict of interest. No writing assistance was utilized in the production of this manuscript.

\section{References}

1. Alraies A, Alaidaroos NYA, Waddington RJ, Moseley R, Sloan AJ. Variation in human dental pulp stem cell ageing profiles reflect contrasting proliferative and regenerative capabilities. BMC Cell Biol 2017;18:12

2. Samuel SS, Ross BJ, Rebekah G, Koshy S. Natal and Neonatal Teeth: A Tertiary Care Experience. Contemp Clin Dent. 2018;9:218-222.

3. Adekoya-Sofowora CA. Natal and neonatal teeth: a review. Niger Postgrad Med J. 2008;15:38-41.

4. Yen VA, Kuppuswami N. Incidence of Natal Teeth in Newborns in Government Medical College and Hospital, Chengalpattu: A Pilot Study. J Clin Diagn Res 2017;11:ZC86-ZC88.

5. Karaöz E, Doğan BN, Aksoy A, Gascar G, Akyüz S, Ayhan S et al. Isolation and in vitro characterisation of dental pulp stem cells from natal teeth. Histochem Cell Biol 2010;133:95-112.

6. Akpinar G, Kasap M, Aksoy A, Duruksu G, Gacar G, Karaöz E. Phenotypic and proteomic characteristics of human dental pulp derived mesenchymal stem cells from a natal, an exfoliated deciduous, and an impacted third molar tooth. Stem Cells Int 2014;2014:457059.

7. Kinzebach S, Bieback K. Expansion of mesenchymal stem/stromal cells under xenogenic-free culture conditions. In: Weyand B, Dominici M, Hass R, Jacobs R, Kasper C, editors. Mesenchymal Stem Cells - Basics and Clinical Application I. Advances in Biochemical Engineering/ Biotechnology, vol 129. Berlin: Springer; 2012.

8. Spees JL, Gregory CA, Singh H, Tucker HA, Peister A, Lynch PJ et al. Internalized antigens must be removed to prepare hypoimmunogenic mesenchymal stem cells for cell and gene therapy. Mol Ther 2004;9:747-756.

9. Weyand B, Dominici M, Hass R, Jacobs R, Kasper C. Mesenchymal stem cells: basics and clinical application II. Berlin: Springer; 2013.

10. Suchánek J, Suchánková Kleplová T, Řeháček V, Browne KZ, Soukup T. Proliferative capacity and phenotypical alteration of multipotent ecto-mesenchymal stem cells from human exfoliated deciduous teeth cultured in xenogeneic and allogeneic media. Folia Biol-Prague 2016;62:1-14.

11. Suchánková Kleplová T, SoukupT, Řeháček V, Suchánek J. Human plasma and human platelet-rich plasma as a substitute for fetal calf serum during long-term cultivation of mesenchymal dental pulp stem cells. Acta Med-Hradec Králové 2014;57:119-126.

12. Suchánek J, Browne KZ, Suchánkova Kleplová T, Mazurová Y. Protocols for dental-related stem cells isolation, amplification and differentiation. In: Zavan B, Bressan $E_{1}$ editors. Dental stem cells: regenerative potential. stem cell biology and regenerative medicine. Humana Press Cham 2016;27-56.

13. Petersen $T$, Niklason L. Cellular lifespan and regenerative medicine. Biomaterials 20017;28:3751-3756.

14. Mokry J, Soukup T, Micuda S, Karbanova J, Visek B, Brcakova E, et al telomere attrition occurs during ex vivo expansion of human dental 
pulp stem cells. J Biomed Biotechnol 2010;673513.

15. Suchánek J, Nasry SA, Soukup T. The Differentiation potential of human natal dental pulp stem cells into insulin-producing cells. Folia BiolPrague 2017;63:132-138.

16. Armanios M, Blackburn EH. The telomere syndromes. Nat Rev Genet 2012;13:693-704.

17. Izadpanah R, Trygg C, Patel B, Kriedt C, Dufour J, Gimble M, et al. Biologic properties of mesenchymal stem cells derived from bone marrow and adipose tissue. J Cell Biochem 2006;99:1285-1297.

18. Gronthos S, Brahim J, Li W, Fisher LW, Cherman N, Boyde A, et al. Stem cell properties of human dental pulp stem cells. J Dent Res. 2002;81:531-535.

19. Miura M, Gronthos $S$, Zhao M, Lu B, Fisher LW, Robey PG et al. SHED: stem cells from human exfoliated deciduous teeth. PNAS. 2003;100:5807-5812.

20. Kerkis I, Kerkis A, Dozortsev D, Stukart-Parsons GC, Gomes Massironi $\mathrm{SM}$, Pereira LV et al. Isolation and characterization of a population of immature dental pulp stem ce Ils expressing 0CT-4 and other embryonic stem cell markers. Cells Tissues Organs 2006;184:105-116.

21. Jo YY, Lee HJ, Kook SY, Choung HW, Park JY, Chung JH, et al., Isolation and characterization of postnatal stem cells from human dental tissues. Tissue Eng 20017;13:767-773.

22. Yoshimura K, Shigeura T, Matsumoto D, Sato T, Takaki Y, Aiba-Kojima $E_{1}$ et al. Characterization of freshly isolated and cultured cells derived from the fatty and fluid portions of liposuction aspirates. J Cell Physiol 2006;208:64-76.

23. Phinney DG, Sensebe L. Mesenchymal stromal cells: Misconceptions and evolving concepts. Cytotherapy 2013:15:140-145.

24. Mitchell JB, Mclntosh K, Zvonic S, Garrett S, Floyd ZE, Kloster A, et al. Immunophenotype of human adipose derived cells: Temporal changes in stromal associated and stem cell-associated markers. Stem Cells 2006;24:376-385.

25. Zhang N, Chen B, Wang W, Chen C, Kang J, Deng SO, et al. Isolation, characterization and multi-lineage differentiation of stem cells from human exfoliated deciduous teeth. Mol Med Rep 2016;14:95-102.

26. Mehrabani D, Mahdiyar P, Torabi $K$, Robati $R$, Zare $S$, Dianatpour $M$, et al. Growth kinetics and characterization of human dental pulp stem cells: Comparison between third molar and first premolar teeth. J Clin Exp Dent 2017;9:e172-e177.

27. Quirici N, Soligo D, Bossolasco P, Servida F, Lumini C, Deliliers GL. Isolation of bone marrow mesenchymal stem cells by anti-nerve growth factor receptor antibodies. Exp Hematol. 2002;30:783-791.

28. Branch MJ, Hashmani K, Dhillon DRE, Dua HS, Hopkinson A. Mesenchymal stem cells in the human corneal limbal stroma. Invest Ophth Vis Sci 2012;53:5109-5116.

29. Kopher RA, Penchev VR, Islam MS, Hill KL, Khosla S, Kaufman DS. Human embryonic stem cell-derived CD341 cells function as MSC progenitor cells. Bone 2010;47:718-728.

30. Hadaegh Y, Niknam M, Attar A, Maharlooei MK, Tavangar MS, Aarabi AM et al. Characterization of stem cells from the pulp of unerupted third molar tooth. Indian J Dent Res 2014;25:14-21.

Received July 1, 2018 Accepted September 14, 2018 